\title{
HETEROTOPIC OSSIFICATION
}

\author{
A Clinical Study of its possible Relationship to Trauma
}

\author{
J. R. SILVER, M.B., B.S., M.R.C.P.ED. \\ Liverpool Regional Paraplegic Centre, Promenade Hospital, Southport
}

IT is with great pleasure that I make this contribution to the Festschrift on the occasion of Sir Ludwig Guttmann's seventieth birthday. Sir Ludwig was trained by Professor Otfrid Foerster in the great German tradition of neurophysiology with emphasis on research being an integral part of clinical practice. In his early days at Breslau he made many important contributions to our knowledge of the autonomic nervous system. On his arrival in England he resumed his research work in conjunction with David Whitteridge and many other distinguished physiologists, neurologists and anatomists at Oxford. Upon his appointment as Director of the Ministry of Pensions Spinal Unit at Stoke Mandeville Hospital in 1944 (despite the exacting nature of his clinical duties), he never relinquished his research interests, producing several classical physiological papers on autonomic hyperreflexia, and on temperature regulation in tetraplegic patients. It was always his desire to develop this side of the work and I was fortunate to work at the Spinal Centre initially as a Registrar from I956 to I 957 and subsequently as Research Physiologist between 1962 and 1965 . Those years profoundly influenced my thinking and I offer this paper in the hope that it will give Sir Ludwig pleasure since he has always stressed that in the first instance research should be based upon accurate clinical observation.

Heterotopic ossification has been recognised as a complication of paraplegia since it was first described by Dejérine and Ceillier in I9I8. However, little is known about its aetiology. Leriche and Policard (1926) suggested that it was due to the transformation of mature connective tissue into a primitive state as a result of trauma or infection and that this damaged tissue subsequently became ossified. Damanski (I96I) supported this view, but Hardy and Dickson (I963) in the most recent paper on this subject were unable to establish any relationship between trauma and the development of this condition.

In order to elucidate this problem further an analysis was made of 124 patients admitted soon after injury to this Centre between I963 and I968 inclusive. Traumatic cases were studied, the majority being admitted early, within I4 days of injury. Cases of paraplegia due to disease of the nervous system were not included since many of them had had prolonged periods of treatment elsewhere.

The presence of heterotopic ossification was assessed at the hip joints by studying the X-rays carried out for the routine intravenous pyelogram and cystogram. This method of assessment is substantially similar to that employed by Damanski, and Hardy and Dickson also stated that special views were not taken of these joints. In a small number of patients direct X-rays of the hip joints were taken. It is recognised that heterotopic ossification may have taken place in other joints, such as the knees and in the case of tetraplegics the shoulders, but routine views of these joints were not available, nor was any histological material.

Incidence. Seventeen patients out of a total of I 24 admissions developed heterotopic ossification, an incidence of 13.6 per cent., its occurrence year by year compared with the total numbers of patients admitted being shown in Table I. A summary of the individual case histories of the patients with relevant factors are presented in Table II. 


\section{TABLE I}

Incidence of Heterotopic Ossification among Patients admitted to the Centre during 1963-1968 Inclusive

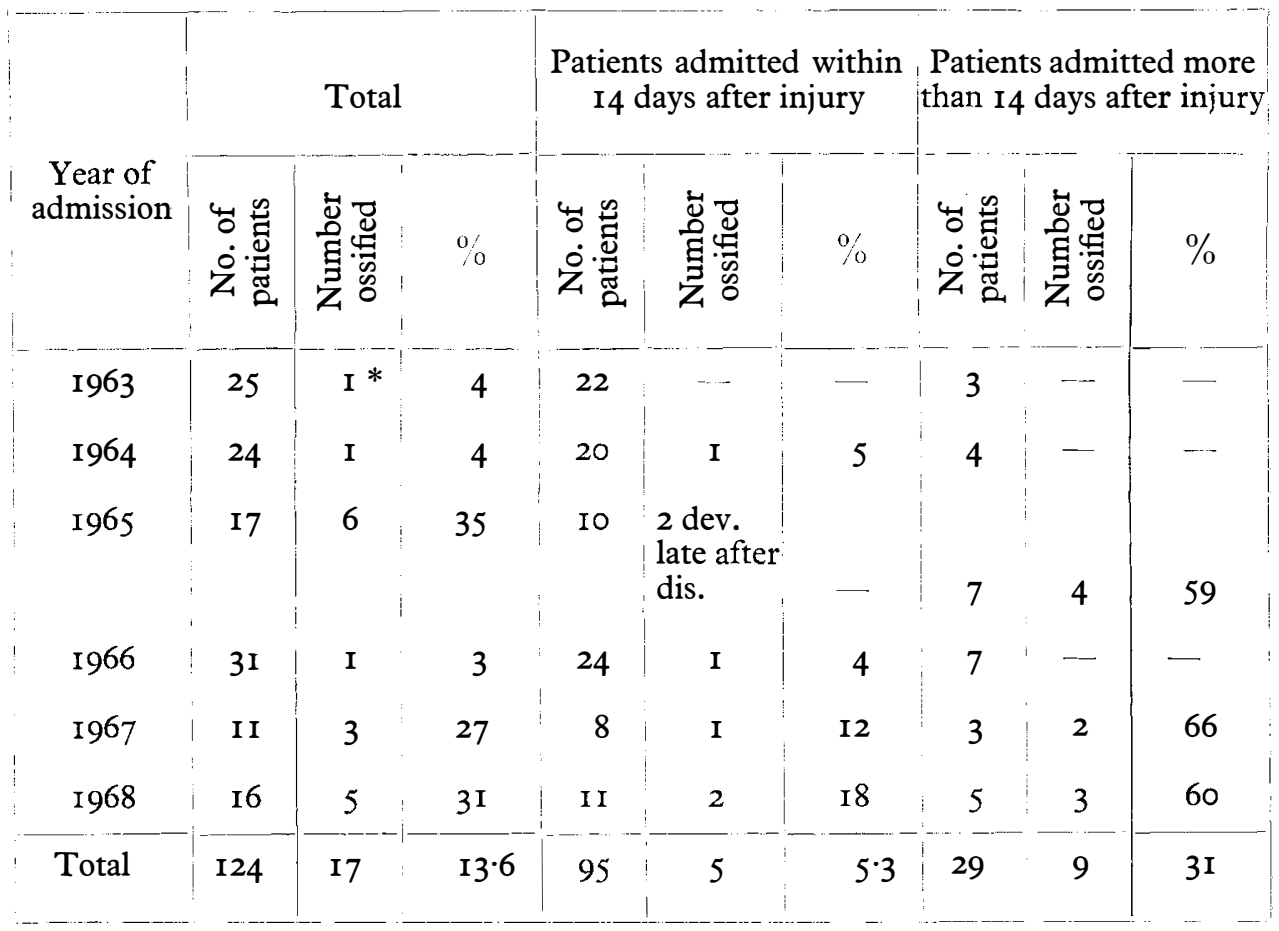

* Developed after discharge from centre.

Heterotopic Ossification associated with Pressure Sores. Seven patients developed heterotopic ossification in association with pressure sores; in four it fulfilled the description of Hardy and Dickson in that the ossification was situated superficially above the greater trochanter, thus corresponding to the perimeter of an undermined area caused by a pressure sore (fig. I). In three patients it was more extensive, surrounding the whole neck of the femur, and appeared to resemble the ossification described by Hardy and Dickson in cases of septic arthritis, although this was not recorded in the notes as having occurred in these cases.

Four patients were admitted at a considerable interval after their initial injury, I 50, I 50, I60 and 37I days respectively, with extensive pressure sores and ossification already present on admission. A further two patients who were admitted early, less than I4 days after injury, developed their sores and ossification after being discharged to unsatisfactory accommodation. One tetraplegic patient (the only patient in this series), in I964 unfortunately developed sores whilst under treatment at this Centre. These sores developed soon after injury in conjunction with pneumonia and turning proved difficult as the staffing of the Centre was not at its present level.

Delayed Admission. The importance of early admission to a spinal centre with the provision of adequate treatment was stressed by Damanski in I96I and is 
TABle II

Clinical Details of the Patients who developed Heterotopic Ossification

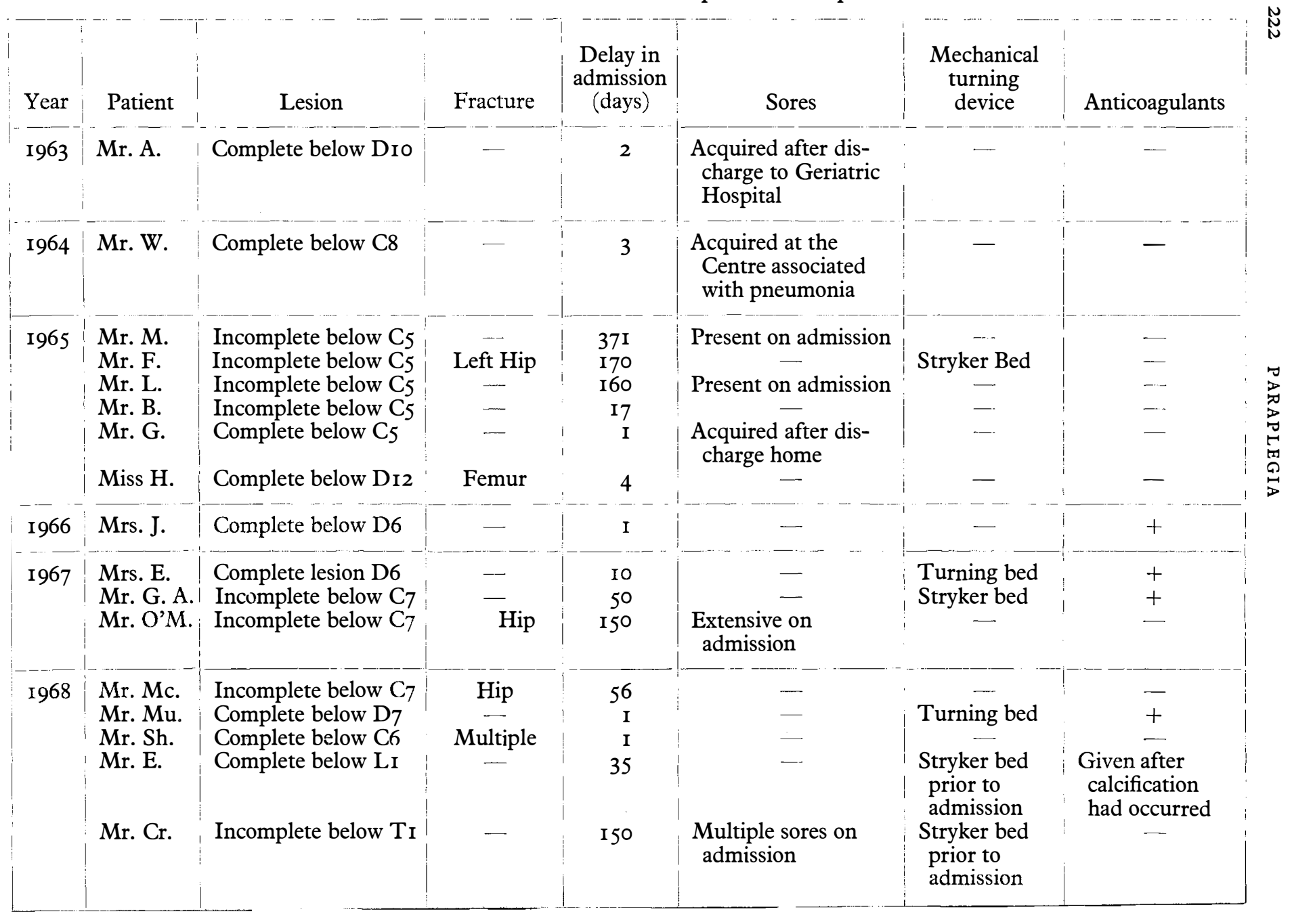




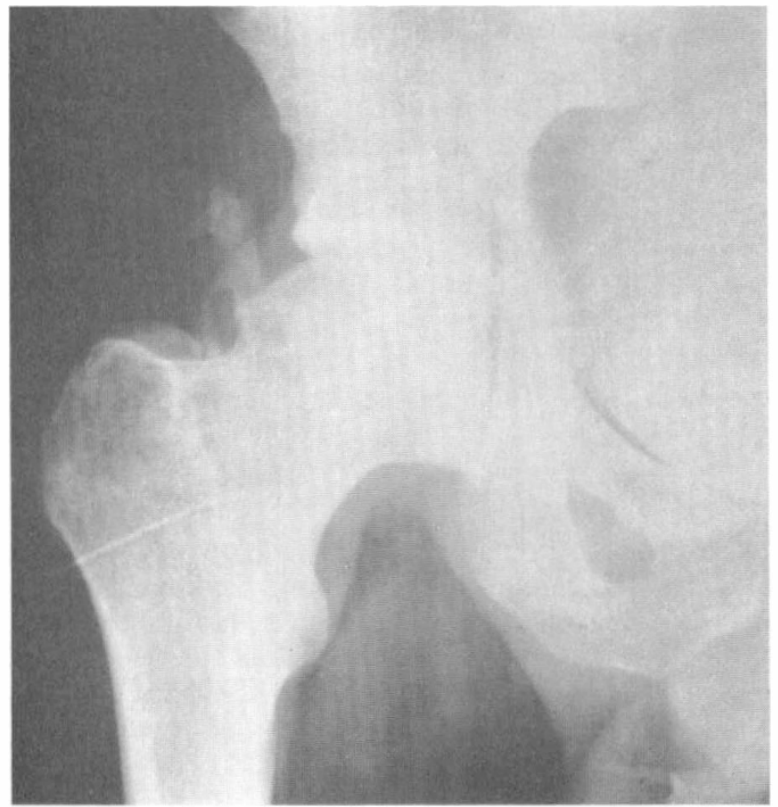

FIG. I

New bone formation in association with a trochanteric pressure sore; note its superficial distribution and its absence in the adductor region.

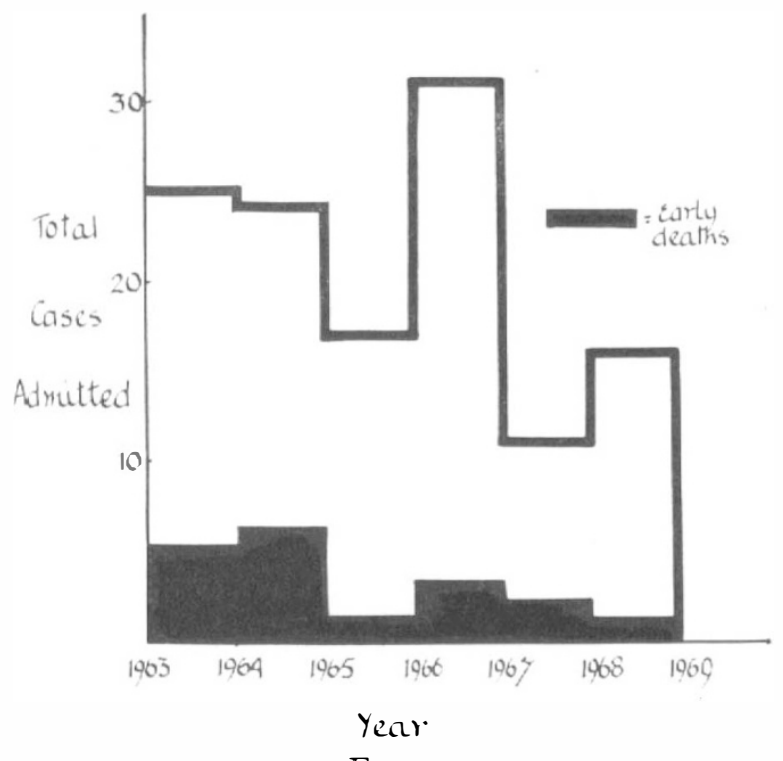

FIG. 2

Early mortality among the patients admitted to the Centre I963 to I968 inclusive. 
confirmed by the present findings. Only five of the 95 patients admitted within I4 days of injury developed ossification during their first hospital admission, an incidence of 5 per cent.

In contrast, of the 29 admitted more than I4 days after injury, 9 patients developed heterotopic ossification, an incidence of $3 \mathrm{I}$ per cent. This was frequently severe, the whole neck of the femur being involved leading to a fixed deformity of the hip joint.

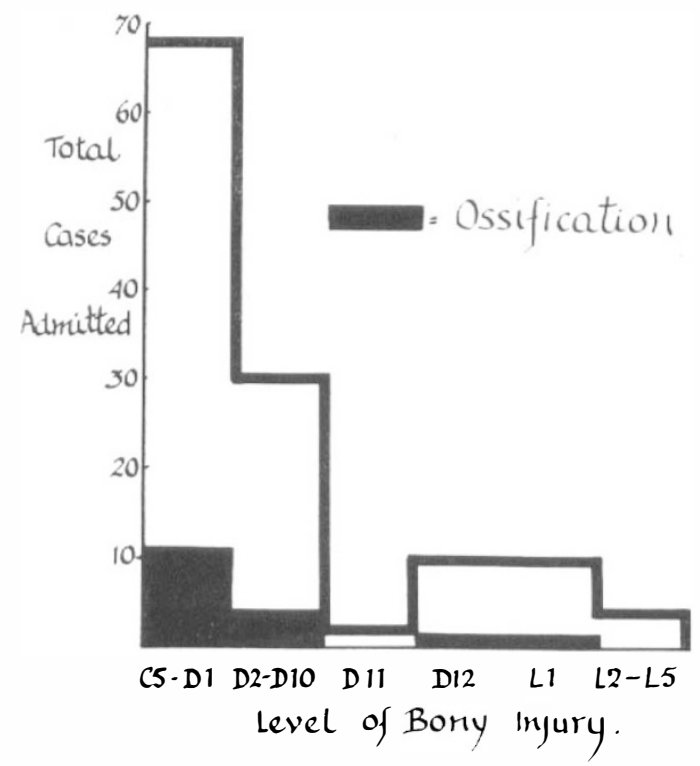

FIG. 3

Heterotopic ossification correlated with the level of the injury.

Level of the Injury. The pattern of admission to this Centre, in common with others in the United Kingdom, has changed over the last decade. Many more patients with tetraplegia, resulting from cervical injury, are being admitted. In Damanski's series these accounted for only 25 per cent. of the total admissions (and of these only 54 were admitted within I4 days of injury), whereas in this series 67 of the I24 patients had cervical injuries and 94 patients were admitted within I 4 days of injury. Not only are many more cervical patients being admitted to the Centre but owing to a better understanding of the treatment they are surviving longer (fig. 2). The early mortality, that is death within three months of injury among the cervical patients in 1968 was only 12.5 per cent., whereas the overall acute mortality for all the cervical patients admitted to the Centre between 1947 and 1967 was 18.5 per cent. (Silver \& Gibbon, I968). It is hardly surprising that the largest number of cases of heterotopic ossification occurred in cervical injuries, there being I I cases (I6.4 per cent.); if those cases are excluded who died within I4 days, since they did not live long enough to develop ossification, the incidence rose to 8 per cent. It would appear that patients with cervical injuries are particularly liable to develop heterotopic ossification, thus substantiating Damanski's 
findings (fig. 3). In his series the commonest injury was at $\mathrm{LI}_{\mathrm{I}}$, but there was a high incidence of ossification in extension injuries to the cervical spine, i.e. 27 per cent. The reason for this may be that elderly patients with such an injury are particularly difficult to nurse owing to their flexor spasms and their tendency to develop sores around the hips.

New Bone Formation without Sepsis (True Heterotopic Ossification). In seven patients new bone formation appeared without there being any evidence of local tissue damage or infection. It usually appeared first in the region of the adductor muscles and initially was not very extensive. In no case did it cause any disability at any stage. Strikingly in six of the patients it was unilateral and in three of these there was a remarkable relationship to trauma produced by passive movements of the lower limbs.

\section{CASE HISTORIES}

I. Mrs. J., a 20-year-old woman, sustained a complete cord lesion at D6 as the result of a car accident on 4.I2.66. She had no other injuries and was admitted to the Centre the following day. Some Io days after injury she complained of chest pain and the left leg was observed to be swollen and hot. A presumptive diagnosis of pulmonary embolism was made, secondary to deep vein thrombosis in the left leg. She was placed on anticoagulant therapy (phenindione) and movements of the left leg were discontinued. Movements of the right leg were continued and she made an uneventful rehabilitation. She got out of bed on I8.I.67 but X-rays on 8.3.67 showed slight ossification around the right hip. At no stage had she complained of any disability in the right leg and by 22.5 .67 she was standing, cooking, dressing and undressing herself and was virtually independent. She was discharged home on 23.6.67 to look after her young children and husband. When she returned for a check-up on 27.I I.68, although there was no disability in her right hip the ossification was much more extensive.

2. Mr. G., aged 45, sustained an incomplete tetraplegia as the result of a fracture dislocation of his cervical spine in a diving accident on 26.6.67 in the United States. An open reduction of the fracture dislocation was carried out on 5.8.67 and he was turned on a Stryker frame, Crutchfield tongs for traction being inserted. He was admitted to the Centre on I6.9.67 and at that stage he was in very good health with no pressure sores but his initial chest X-ray showed some collapse of the anterior basal segment of the right lung. On 21.9.67 he was observed to have swelling of his right lower limb, particularly around the ankle and the knee. A presumptive diagnosis of deep vein thrombosis was made. Movements of his right lower limb were discontinued but movements of the left lower limb were continued, anticoagulants being instituted. On 2.I0.67 he was observed to have swelling and tenderness in his left adductor muscles, but the hip X-ray was normal. On I4.I I.67 an X-ray revealed heterotopic ossification in his left hip in the position of the swelling (fig. 4). The right hip was quite normal. He was discharged home on 5.I.68 and although he had no disability in his left hip at that time the ossification was more extensive.

3. Mrs. Ent., a 49-year-old married woman who was seated in the front of a car on I 7.I I.67 when another car drove into the back of her, sustained a complete cord lesion below D6. An open reduction was carried out on the following day (I8.I I.67) and she was admitted to the Liverpool Regional Paraplegic Centre nine days later. She commenced regular passive movements to her lower limbs and was treated on a turning bed. On 29.12.67 swelling of her right lower limb was observed and passive movements were discontinued on this side but continued on the left. On I2.I.68 she complained of chest pain which appeared to be pleuritic and a presumptive diagnosis of pulmonary embolism was made, thus anticoagulant therapy was started. On 2.I2.68 she was balancing in the gymnasium pursuing an uneventful rehabilitation, and becoming independent in a wheelchair. On 22.3.68, following a minor fall, her left hip was X-rayed, this revealing a little $2 \mathrm{R}^{*}$ 


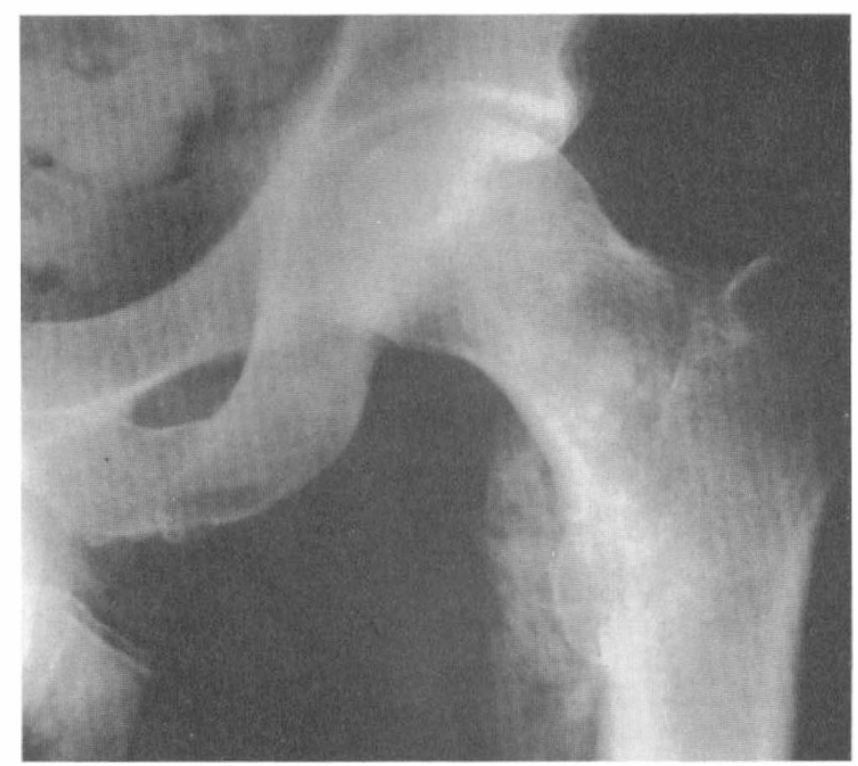

FIG. 4

Mr. G., I4.I I.67: X-ray left hip reveals heterotopic ossification in the adductor muscles following passive movements.

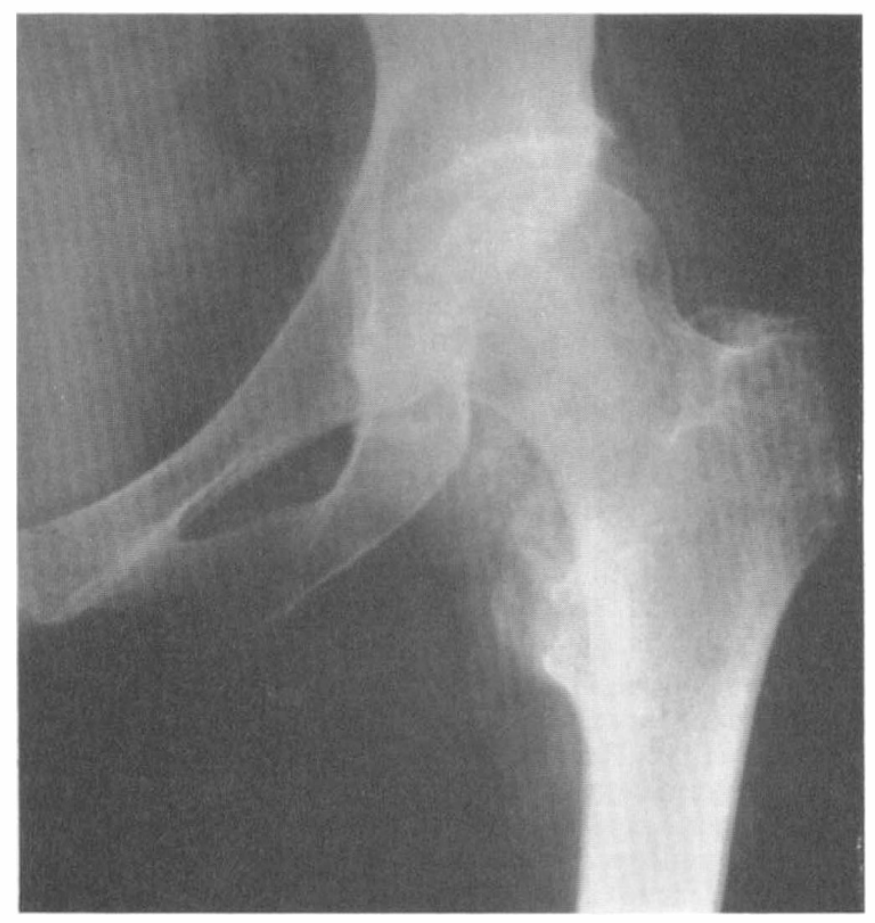

FIG. 5

Mrs. E., X-ray 31.5.68 six months after her injury. Note ossification in the adductor region following passive movements of this lower limb. 
new bone formation but becoming more extensive by 31.5.68 (fig. 5). The right hip which had not been moved had no ossification whatsoever.

Two other patients developed ossification following treatment at other hospitals on a Stryker frame. The circumstances of the use of this piece of equipment point to there having been local trauma to the limb at the site of ossification.

4. On I5.I0.68 Mr. E., a 25-year-old manual worker, sustained a complete spinal cord lesion below DI2 as the result of a crane jib falling on to his back; there were no

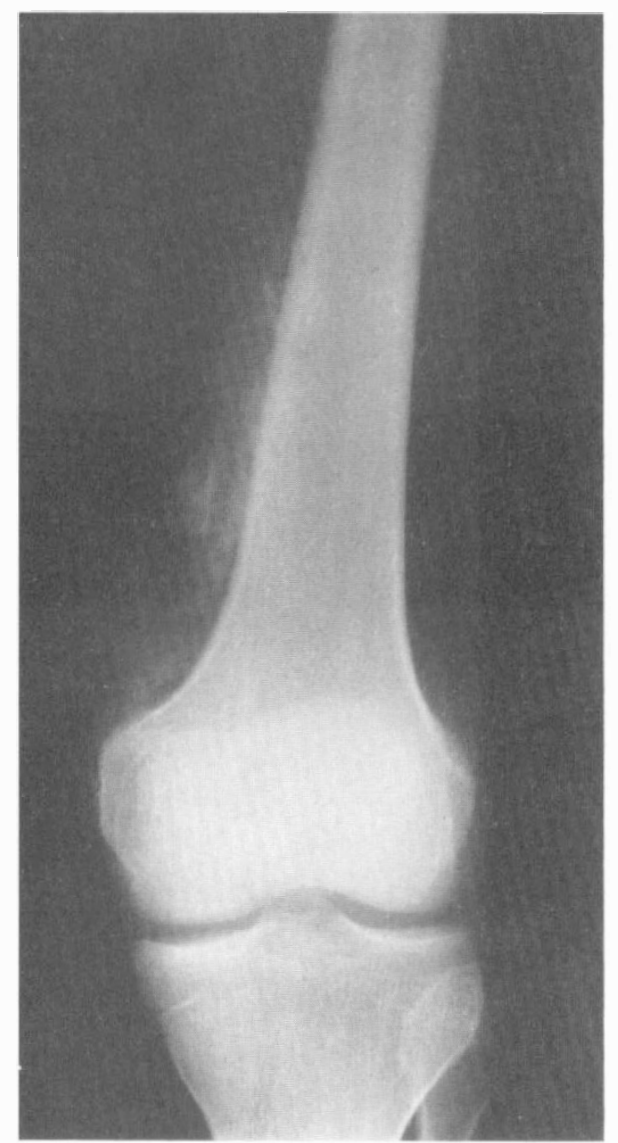

Fig. 6

X-ray left knee. Thirty-five days after injury early ossification associated with pressure from a Stryker frame.

injuries or bruising of his lower limbs observed at the time of his admission to hospital. A plate was inserted to fix his spine and he was treated on a Stryker frame. The frame was uncomfortable as it was too small and pillows were placed beneath his knees to give support. Some 20 days after the injury his left knee was observed to be swollen. Thirtyfive days after injury he was transferred to the Liverpool Regional Paraplegic Centre where the swelling was noted. An X-ray revealed early ossification although there were no sores or fractures around the knee (fig. 6). He was treated with anticoagulants and the passive movements to his lower limbs were discontinued. 


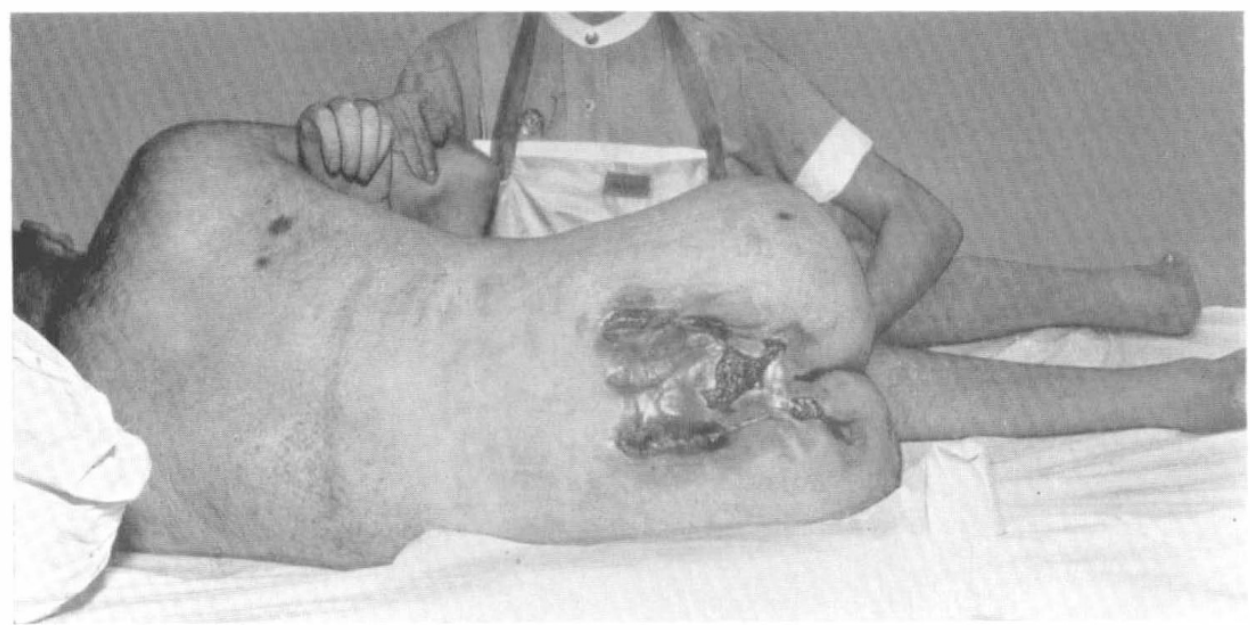

FIG. 7

Mr. C. Extensive sores associated with the use of a Stryker frame; note the linear nature of the sores on his back.

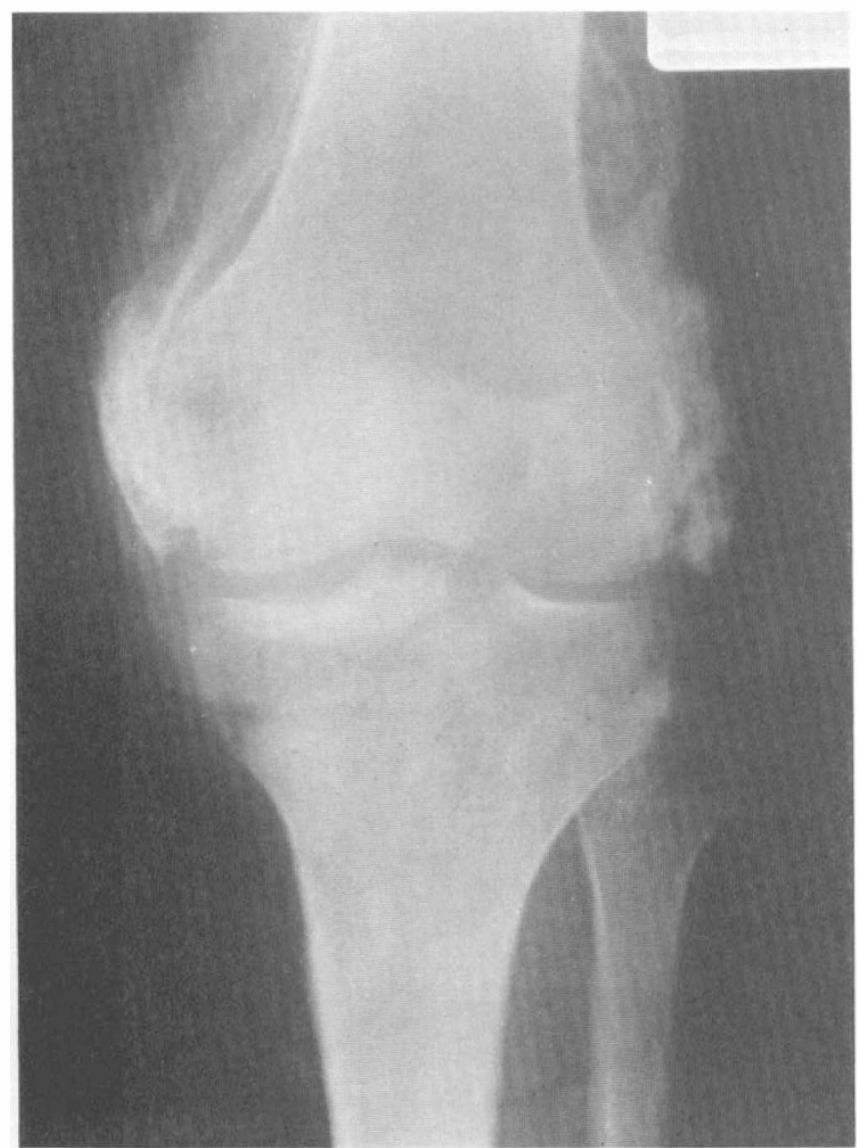

FIG. 8

Mr. C. Extensive ossification of the knee associated with the use of a Stryker frame. 
5. A further patient sustained a fracture of $\mathrm{C}_{7}$ on $\mathrm{D}_{\mathrm{I}}$ and was treated for some months at another hospital on a Stryker frame. He too stated that the Stryker frame was too narrow and that he acquired sores on his face and chest from the straps, and on his hips from the sides of the Stryker frame. He had superficial sores on his knees as a pillow had been placed beneath them to keep his knees clear of the canvas of the Stryker. X-ray revealed extensive ossification of his hips in association with the pressure sores and around his knees (figs. 7 and 8).

All five patients showed a striking relationship to trauma in the production of their ossification. Three other patients showed unilateral ossification and in whom the relationship to trauma was not so well established. One was treated with anticoagulants on a turning bed at this Centre. Another sustained severe multiple injuries following a fall beneath a railway train; these included a head injury, a complete C6 lesion, a shattered right elbow and bilateral amputation of his lower limbs.

\section{DISCUSSION}

The aetiology of heterotopic ossification is ill understood but it is associated with paralysis and there is a higher incidence in patients who do not receive adequate initial treatment. Hardy and Dickson (I963) made an important contribution by distinguishing between new bone formation occurring in the presence of gross local sepsis (which was sclerotic, without lamellar bone formation, Haversian systems or myeloid tissue, not unique to paraplegia since it occurs in patients with other chronic infections of bone), and heterotopic ossification which only occurs in the presence of paralysis, in the absence of infection, and is histologically distinct as it appears to be true bone with Haversian systems. They were unable to offer any evidence as to its aetiology, nor could they relate it to trauma or to the level of the lesion, but suggested on histological grounds that it was distinct from ossification occurring in a haematoma.

The occurrence of early ossification in this series of patients who were admitted almost immediately after injury, and who never developed severe urinary infection involving the kidneys constitutes evidence against this heterotopic ossification being secondary to a renal metabolic disturbance.

This series seems to offer some support for the relationship of heterotopic ossification to trauma, either by passive movements or by the use of Stryker frames and turning beds, since all three patients who had unilateral movements in the non-swollen leg developed ossification, whereas the swollen leg which was not manipulated remained free of ossification.

A further point of interest is the relationship of ossification occurring in the years since 1962. The method of treatment at this Centre has changed in some detail, which may be relevant to the development of ossification between the years I962 and I968. Until July I965 the staffing of the Centre was not at its present level and the policy with regard to treatment of complete lesions was to mobilise the patients as soon as the pain at the fracture site had subsided (often within a few days), and in incomplete lesions to mobilise the patients as soon as the fracture was thought to be stable. The patients consequently were in bed only a short period of days. There was no full time physiotherapy staff attached exclusively to the Centre so that patients did not receive as much passive movements as was considered desirable. Anticoagulant drugs were only given in the event of a deep vein thrombosis or pulmonary embolism.

In 1965 the policy with regard to treatment was changed, all patients being 
kept in bed for a minimum of three months whether the lesion was complete or incomplete, in order to enable the fracture-dislocation to stabilise. Additional physiotherapy staff were appointed to ensure that regular passive movements for 20 minutes per leg twice a day were given. Turning beds were purchased in 1967. The policy with regard to anticoagulant therapy changed. In 1967 all patients with presumed deep vein thrombosis were given anticoagulants, and in 1968, following a fatality due to a pulmonary embolus in a complete tetraplegic, all new admissions were placed on anticoagulants. Although the numbers are small it is striking that with the regime of treatment as carried out in 1963-64 (that is early mobilisation and few passive movements with no anticoagulant therapy), only one patient out of 42 developed heterotopic ossification and in that patient there was an associated pressure sore; whereas with the regime followed during 1966, I967 and 1968, four patients out of 43 developed heterotopic ossification.

It would appear that change in treatment comprising increased passive movements, anticoagulants and turning beds has been associated with an increased incidence of ossification. The patients all stated that, although the turning bed is more comfortable when the actual turn is being carried out, it is much firmer and harder to lie on compared with the use of pillows and packs. This is supported by Damanski (196I) who stated that there was a higher incidence of ossification in patients treated on plaster of Paris beds. Despite the higher incidence of ossification with this regime, it is still considered well worth while since the incidence of pulmonary embolism has fallen dramatically and all chest complications, previously thought to be pneumonia, have also diminished. The presumption is that many of the cases previously diagnosed as pneumonia had in fact pulmonary infarcts. This has made the nursing of the patients much easier and has abolished pressure sores.

\section{SUMMARY AND CONCLUSION}

The incidence of heterotopic ossification among I 24 traumatic spinal injuries admitted soon after injury has been analysed; 17 developed heterotopic ossification. This occurred in the majority of cases soon after injury and was not associated with gross renal sepsis. In a small number of cases there was a clear relationship with trauma, either produced by passive movements or from a Stryker bed.

I am grateful to Mr. M. Damanski, Mr. A. Sutcliffe Kerr and Dr. A. Hardy for helpful criticism of this work.

I am particularly grateful to Dr. K. D. F. Morle, Consultant Radiologist, Miss M. A. Butler-Wright and all the staff of the X-ray Department at Southport for their constant willing co-operation in this study.

I wish to thank the National Fund for Research into Poliomyelitis and other Crippling Diseases for a grant with which part of the study was carried out.

\section{REFERENCES}

Damanski, M. (1961). F. Bone ft Surg. 43-B, 286.

Dejerine, MMe \& Ceillier, A. (I9I8). Revue neurol. 25, I59.

HaRdy, A. G. \& Dickson, K. W. (1963). F. Bone ft Surg. 44-B, 76.

LeRICHe, R. \& PliCARD, A. (I926). Les Problémes de le Physiologie Normale et Pathologique de l'Os. Paris: Masson.

Silver, J. R. \& GibBon, N. O. K. (I968). 